Proceedings

\title{
Beware of Oysters. Rapid Advance of non-Native Species in Tropical Pacific Islands ${ }^{+}$
}

\author{
Alba Ardura *, Almudena Gonzalez-Sanz, Laura Clusa, Serge Planes, Eva Garcia-Vazquez \\ * Correspondence: arduraalba@uniovi.es
}

Citation: Alba Ardura *, Almudena Gonzalez-Sanz, Laura Clusa, Serge Planes, Eva Garcia-Vazquez. Beware of oysters. Rapid advance of non-native species in tropical Pacific islands. Proceedings 2021, 68, $\mathrm{x}$. https://doi.org/10.3390/xxxxx

Publisher's Note: MDPI stays neutral with regard to jurisdictional claims in published maps and institutional affiliations.

Copyright: (C) 2021 by the authors. Submitted for possible open access publication under the terms and conditions of the Creative Commons Attribution (CC BY) license (http://creativecommons.org/licenses /by/4.0/).

\begin{abstract}
Contrary to what is normally thought, any ecosystem is fragile in itself. That is, if the correct pressure is being applied over it. Coral reefs are usually robust, balanced, dynamic, selfregulating ecosystems that will have greater or lesser populations of all the species of plants and animals that live there, depending on the climate conditions: water temperature, amount of sunlight, salinity, etc. But there are situations in which this balance can be quickly and easily thrown out of whack: among others, it is happening when new coming species arrive for disturbing the host ecosystem. Marine biological invasions are one of the main causes of biodiversity losses, agravated in vulnerable habitats such as islands and continental waters. Ports are main entry gates of exotic biota, principally through biofouling and ballast water. Since eradication is more difficult in late than in early invasion stages, early detection of first stages of invasion is essential in conservation biology politics. The main problem is that most species are difficult to detect, especially during early developmental stages (i.e. larval and juvenile stages) and new strategies are needed to effective prevention and early detection of nuisance organisms. They should involve not only port stakeholders and researchers but the whole society because sostenaible development is a priority for any ecosystems and more for Pacific Islands, which are a reflection of Natural Paradise. The principal aim of this work is the development of an early detection, monitoring and control protocol for benthonic NIS in Polynesian ports in order to see the evolution of invasive oyster species. The two exotic species identified during the sampling in different years were the Natal rock oyster, Saccostrea cucullatanative from Indian Ocean and Red Sea and the Frond oyster, Dendostrea frons - native from Caribbean Sea. The Frond oyster (D. frons) was detected only in the three ships sampled in Port of Papeete in 2011, however, in 2018 this oyster was present into the port of Papeete and in Vaiare Ferry and Marina. On the other hand, the Natal rock oyster (S. cucullata) was present only in Pao-Pao port in Moorea Island in 2011, and in Pao-Pao, Vaiare Ferry and Port of Papeete in 2018.
\end{abstract}

Keywords: Barcoding; NIS; benthonic species; French Polynesia; monitoring; early detection 